\title{
Variation of sweet potatoes with respect to source potentials and sink capacities
}

\author{
L. $\mathrm{Li}^{1} \&$ C.H. Kao ${ }^{2}$ \\ ${ }^{1}$ Department of Horticulture, Chinese Culture University, Taipei, Taiwan, Republic of China; \\ ${ }^{2}$ Department of Agronomy, National Taiwan University, Taipei, Taiwan, Republic of China
}

Received 11 July 1988; accepted in revised form 8 August 1989

Key words: Ipomoea batatas, sweet potato, grafting, sink capacity, source potential

\section{Summary}

By using four tester clones either as scions or stocks, source potentials and sink capacities of two groups of 13 and 20 sweet potato clones were measured in 1986 and 1987, respectively. Results obtained in the 1986 trial were generally consistent with those in the 1987 trial, though different clones were used in both trials. There were significant differences in source potentials and in sink capacities among tested clones. Responses of source to sink and of sink to source were also estimated using a regression method. No significant correlation was observed between source potential and response of source to sink. However, sink capacity showed significant relationship with response of sink to source.

\section{Introduction}

Hozyo (1970) and Wilson (1967) suggested that yield of sweet potato was determined primarily by sink capacity rather than source potential. Hahn (1977), on the other hand, has inferred that both source potential and sink capacity can be rate limiting to yield with the latter more important than the former. In our previous work using reciprocal grafts, we concluded that the source potential was more limiting than sink in the first four months, but they are equally important in determining tuberous root yield at 6 months (Li \& Kao, 1985a). Bouwkamp \& Hassam (1988) recently reported that cultivars showing strong sink effects were generally low-yielding.

In a breeding program, it is much easier to evaluate and select for sink capacity (yield) than for source potential (photosynthetic capacity). However, evaluation for source potentials of sweet potatoes is possible because source and sink can be easily exchanged by reciprocal grafting for this purpose. In the present investigation, four tester clones were used as source and sink, respectively, to evaluate source potentials and sink capacities of various experimental sweet potato clones.

\section{Materials and methods}

All experiments were conducted in 1986 and 1987 in an experimental field of Chiayi Agricultural Experiment Station, Chiayi, Taiwan, Republic of China. The soil type was sandy loam.

The four tester clones were C70-245, C70-200, C70-311 and C70-105 which were used in our previous work (Li \& Kao, 1985a). Thirteen and twenty experimental clones were chosen for the 1986 and 1987 trials, respectively, to determine their source potentials and sink capacities. For the 1986 trial, 16 slips of each experimental clone were grafted to each of the four tester clones, and 16 slips of each 


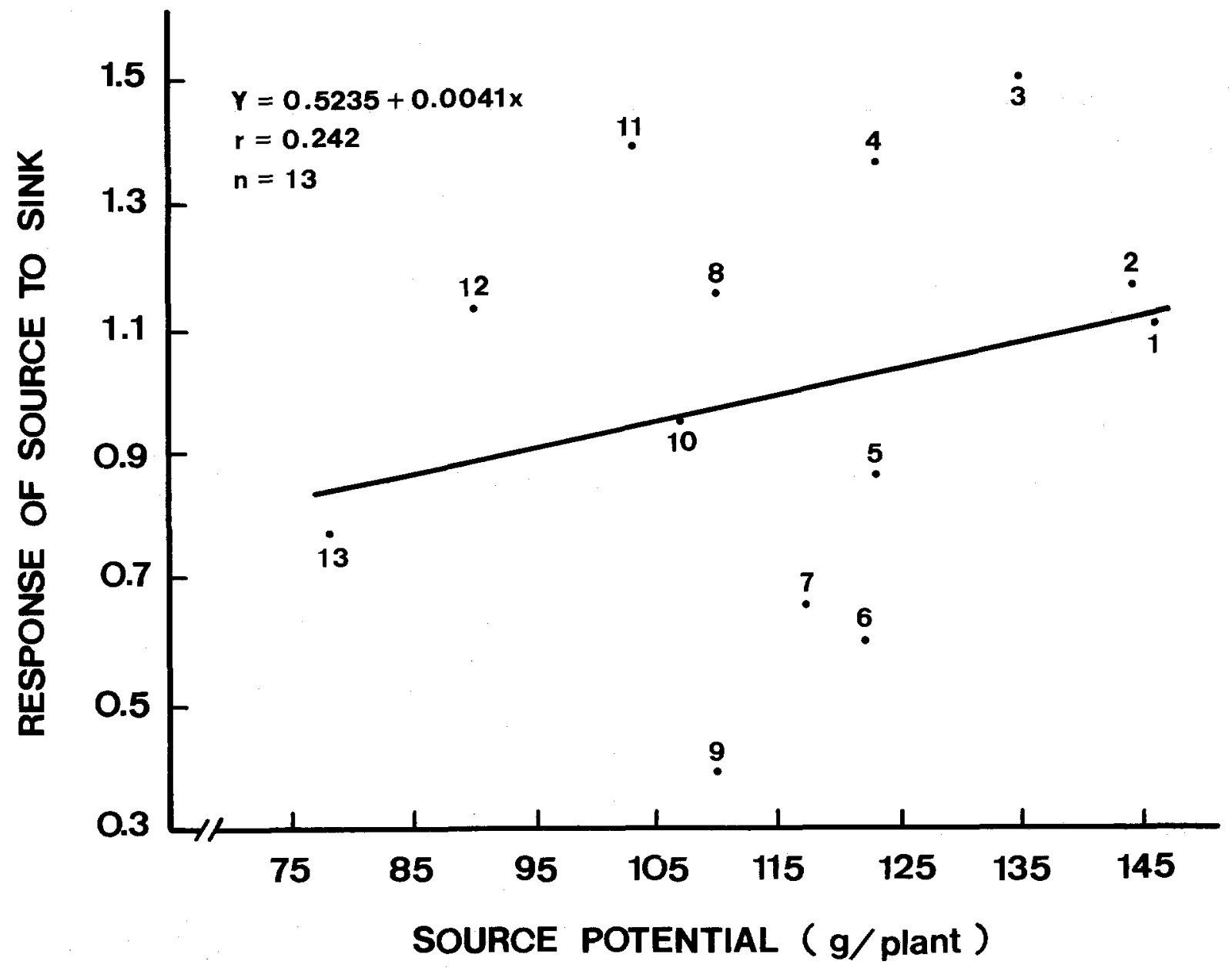

Fig. 1. Relation between source potential (x) and response of source to sink (y) for 13 experimental sweet potato clones (1986 trial). The numbers by points refer to clones ranking in Table 1 .

Table 1. Dry tuberous root yields (g/plant) of the 13 experimental clones grafted to the four tester sweet potato clones (1986 trial)

\begin{tabular}{|c|c|c|c|c|c|c|c|}
\hline \multirow[t]{2}{*}{ Ranking } & \multirow[t]{2}{*}{ Clone tested } & \multicolumn{4}{|l|}{ Stock } & \multirow{2}{*}{$\begin{array}{l}\text { Mean scion } \\
\text { effect }\end{array}$} & \multirow{2}{*}{$\begin{array}{l}\text { Response of } \\
\text { source to sink }\end{array}$} \\
\hline & & $\mathrm{C} 70-245$ & $\mathrm{C} 70-200$ & $\mathrm{C} 70-311$ & C70-105 & & \\
\hline $\begin{array}{r}1 \\
2 \\
3 \\
4 \\
5 \\
6 \\
7 \\
8 \\
9 \\
10 \\
11 \\
12 \\
13\end{array}$ & $\begin{array}{l}\text { C68-220 } \\
\text { C72-769 } \\
\text { C69-27 } \\
\text { C66-51 } \\
\text { C66-24 } \\
\text { C70-244 } \\
\text { C69-29 } \\
\text { C67-249 } \\
\text { C70-220 } \\
\text { C67-59 } \\
\text { C66-18 } \\
\text { C69-61 } \\
\text { C72-637 }\end{array}$ & $\begin{array}{r}177.0 \\
109.7 \\
146.3 \\
133.0 \\
152.1 \\
150.2 \\
154.4 \\
145.7 \\
144.5 \\
152.9 \\
142.3 \\
116.4 \\
94.6\end{array}$ & $\begin{array}{r}171.1 \\
147.9 \\
160.5 \\
120.4 \\
170.6 \\
141.8 \\
110.9 \\
44.6 \\
89.8 \\
78.8 \\
39.4 \\
56.9 \\
39.3\end{array}$ & $\begin{array}{l}162.5 \\
230.1 \\
188.1 \\
184.1 \\
119.1 \\
119.2 \\
120.1 \\
166.6 \\
108.3 \\
126.7 \\
166.9 \\
139.0 \\
119.3\end{array}$ & $\begin{array}{l}73.1 \\
87.7 \\
44.1 \\
54.8 \\
50.3 \\
77.9 \\
83.8 \\
83.9 \\
97.0 \\
68.8 \\
62.7 \\
48.0 \\
57.9\end{array}$ & $\begin{array}{c}145.9 \mathrm{a}^{*} \\
143.9 \mathrm{a} \\
134.8 \mathrm{ab} \\
123.1 \mathrm{abc} \\
123.0 \mathrm{abc} \\
122.3 \mathrm{abc} \\
117.3 \mathrm{abc} \\
110.2 \mathrm{abc} \\
109.9 \mathrm{abc} \\
106.8 \mathrm{abc} \\
102.8 \mathrm{abc} \\
90.1 \mathrm{bc} \\
77.8 \mathrm{c}\end{array}$ & $\begin{array}{l}1.10 \\
1.16 \\
1.50 \\
1.36 \\
0.86 \\
0.60 \\
0.65 \\
1.15 \\
0.39 \\
0.95 \\
1.39 \\
1.13 \\
0.77\end{array}$ \\
\hline \multicolumn{2}{|c|}{ Mean stock effect } & $139.9 a^{* *}$ & $105.5 b$ & $150.0 \mathrm{a}$ & $68.5 \mathrm{c}$ & 116.0 & \\
\hline \multicolumn{2}{|c|}{ Response of sink to source } & 0.57 & 2.23 & 1.02 & 0.18 & & \\
\hline
\end{tabular}

*, ** Means having same letters are not significantly different at $5 \%$ and $1 \%$ level, respectively, by Duncan's Multiple Range Test. 


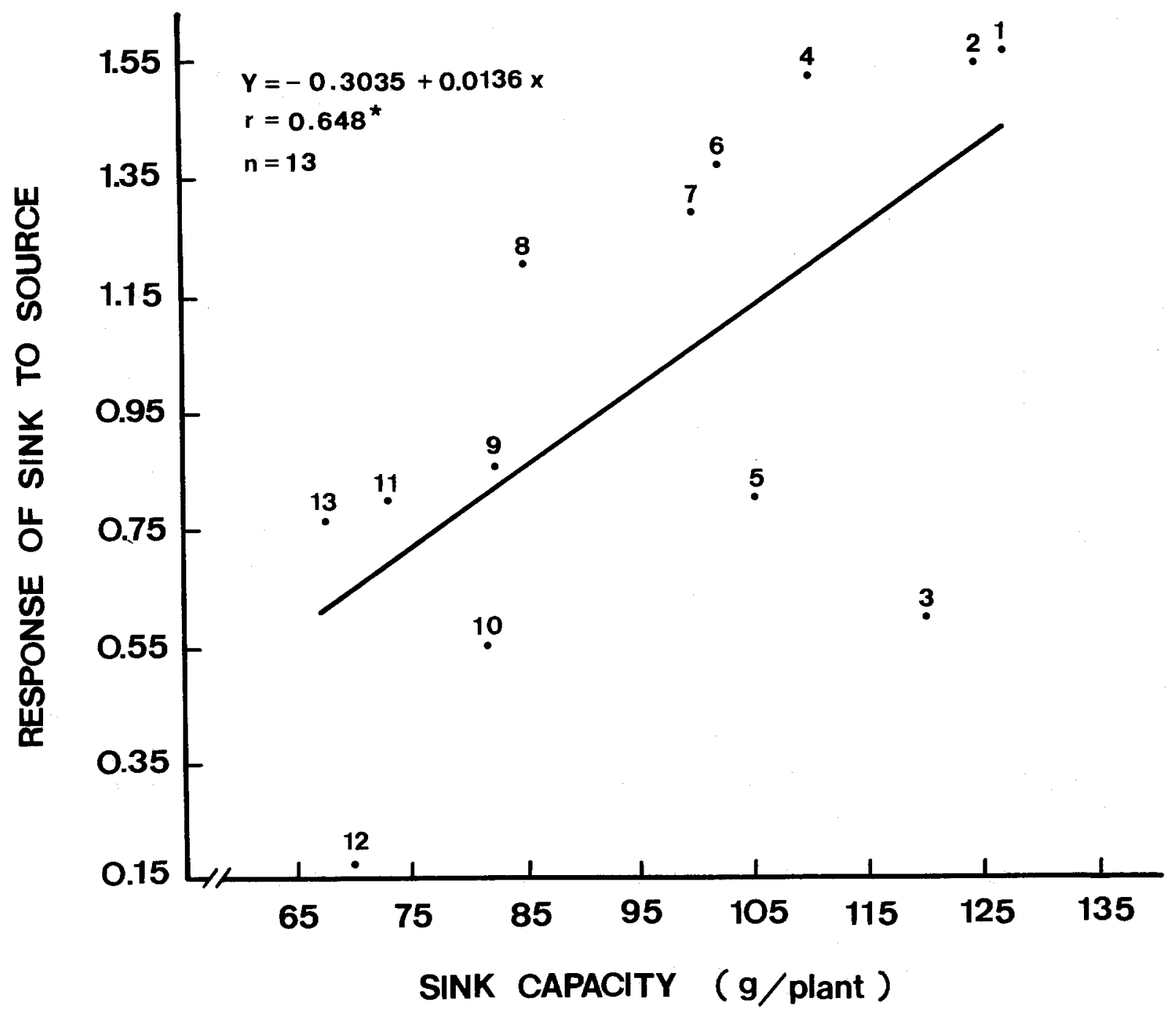

Fig. 2. Relation between sink capacity (x) and response of sink to source (y) for 13 experimental sweet potato clones (1986 trial). The numbers by points refer to clones ranking in Table 2 .

tester clone were grafted to each of the 13 experimental clones. In the trial of 1987,12 slips of each experimental clone were grafted to each of the four tester clones as stock, and 12 slips of each tester clone used as a scion were grafted to each of the 20 experimental clones. About a month after grafting, the grafts were planted in the field at a spacing of $100 \mathrm{~cm}$ between rows and $25 \mathrm{~cm}$ within rows in August 1986 and August 1987. A randomized complete block design was used with four replications. Each plot consisted of four and three plants for the 1986 and 1987 trials, respectively. Fertilizer was applied prior to planting ( $40 \mathrm{~kg} \mathrm{~N}, 40 \mathrm{~kg} \mathrm{P}$ and $80 \mathrm{~kg}$
$\mathrm{K}$ per ha) and at 30 days after planting ( $40 \mathrm{~kg} \mathrm{~N}$ and $80 \mathrm{~kg} \mathrm{~K}$ per ha). Plants were harvested 150 days after planting and dried in the oven at $90^{\circ} \mathrm{C}$ for 2 days. Data of dry tuberous root yield were analyzed. The degrees of responses of source to sink and of sink to source were determined by the regression method proposed by Hahn (1977).

In 1987, yield trial of 20 experimental clones without grafting were also conducted simultaneously. All the experimental conditions and design were similar to those of grafting experiment conducted in 1987. 
Table 2. Dry tuberous root yields (g/plant) of the four tester clones grafted to the 13 experimental sweet potato clones (1986 trial)

\begin{tabular}{|c|c|c|c|c|c|c|c|}
\hline \multirow[t]{2}{*}{ Ranking } & \multirow[t]{2}{*}{ Clone tested } & \multicolumn{4}{|l|}{ Scion } & \multirow{2}{*}{$\begin{array}{l}\text { Mean stock } \\
\text { effect }\end{array}$} & \multirow{2}{*}{$\begin{array}{l}\text { Response of } \\
\text { sink to source }\end{array}$} \\
\hline & & $C 70-245$ & C70-200 & $\mathrm{C} 70-311$ & C70-105 & & \\
\hline 1 & C69-27 & 188.6 & 147.3 & 129.4 & 43.1 & $127.1 a^{*}$ & 1.56 \\
\hline 2 & $\mathrm{C} 70-220$ & 175.3 & 177.6 & 68.2 & 76.5 & $124.4 \mathrm{a}$ & 1.54 \\
\hline 3 & C66-18 & 137.8 & 126.8 & 137.4 & 77.3 & $119.8 \mathrm{ab}$ & 0.59 \\
\hline 4 & C70-244 & 129.8 & 185.4 & 78.8 & 46.2 & 110.1abc & 1.52 \\
\hline 5 & C67-59 & 119.0 & 140.2 & 88.3 & 71.7 & $104.8 \mathrm{abcd}$ & 0.80 \\
\hline 6 & C72-637 & 174.6 & 109.4 & 79.8 & 44.0 & 102.0abcde & 1.37 \\
\hline 7 & C69-29 & 144.2 & 132.5 & 76.4 & 45.8 & 99.7abcde & 1.28 \\
\hline 8 & C69-61 & 122.6 & 112.9 & 80.5 & 23.4 & 84.9 bcde & 1.20 \\
\hline 9 & C67-249 & 146.0 & 75.3 & 44.5 & 61.0 & $81.7 \mathrm{bcde}$ & 0.85 \\
\hline 10 & C68-220 & 79.9 & 101.7 & 112.1 & 32.5 & $81.6 \mathrm{bcde}$ & 0.55 \\
\hline 11 & C66-24 & 95.3 & 99.9 & 56.3 & 40.0 & $72.9 \mathrm{cde}$ & 0.80 \\
\hline 12 & C66-51 & 71.0 & 81.9 & 53.9 & 67.9 & $68.7 \mathrm{de}$ & 0.18 \\
\hline 13 & $C 72-769$ & 75.8 & 114.4 & 31.5 & 47.8 & $67.4 \mathrm{e}$ & 0.76 \\
\hline \multicolumn{2}{|c|}{ Mean scion effect } & $127.7 \mathrm{a}^{*}$ & $123.5 \mathrm{a}$ & $79.8 \mathrm{~b}$ & $52.1 \mathrm{c}$ & 95.8 & \\
\hline \multicolumn{2}{|c|}{ Response of source to sink } & 1.52 & 1.21 & 1.00 & 0.28 & & \\
\hline
\end{tabular}

* Means having same letters are not significantly different at 1\% level by Duncan's Multiple Range Test.

\section{Results}

\section{6 trial}

The source potential of a clone is defined as its mean scion effect and the sink capacity is its mean stock effect. The source potentials and degrees of response of source to sink measured by regression coefficients for the 13 experimental clones are shown in Table 1. There were significant differences at the $5 \%$ level among the source potentials of the 13 clones. There were significant differences at the $1 \%$ level among the sink capacities of the four tester clones. The results presented in Table 1

Table 3. Dry tuberous root yields (g/plant) of the 20 experimental clones grafted to the four tester sweet potato clones (1987 trials)

\begin{tabular}{|c|c|c|c|c|c|c|c|}
\hline \multirow[t]{2}{*}{ Ranking } & \multirow[t]{2}{*}{ Clone tested } & \multicolumn{4}{|l|}{ Stock } & \multirow{2}{*}{$\begin{array}{l}\text { Mean scion } \\
\text { effect }\end{array}$} & \multirow{2}{*}{$\begin{array}{l}\text { Response of } \\
\text { source to sink }\end{array}$} \\
\hline & & C70-245 & C70-200 & $\mathrm{C} 70-311$ & $\mathrm{C} 70-150$ & & \\
\hline 1 & TN 64 & 268.3 & 136.3 & 84.0 & 148.3 & $159.2 \mathrm{a}^{*}$ & 0.11 \\
\hline 2 & C72-130 & 237.1 & 163.6 & 140.6 & 86.9 & 157.1a & 1.29 \\
\hline 3 & C72-324 & 172.4 & 132.4 & 216.9 & 101.4 & $155.8 \mathrm{a}$ & 1.53 \\
\hline 4 & C72-738 & 226.1 & 94.5 & 240.3 & 45.9 & 151.7ab & 2.95 \\
\hline 5 & C72-38 & 152.8 & 92.8 & 221.8 & 129.4 & 149.2ab & 1.15 \\
\hline 6 & C72-769 & 105.0 & 115.8 & 178.7 & 137.4 & $134.2 \mathrm{abc}$ & 0.27 \\
\hline 7 & C70-141 & 103.6 & 193.2 & 190.8 & 22.9 & 127.6abc & 1.81 \\
\hline 8 & TN 67 & 120.7 & 138.1 & 144.8 & 82.7 & 121.6abcd & 0.73 \\
\hline 9 & TN 66 & 156.0 & 110.5 & 125.9 & 90.9 & $120.8 \mathrm{abcd}$ & 0.71 \\
\hline 10 & TN 68 & 132.9 & 112.2 & 152.5 & 62.6 & 115.1bcde & 1.22 \\
\hline 11 & C68-106 & 87.1 & 155.2 & 172.2 & 40.7 & $113.8 \mathrm{bcde}$ & 1.35 \\
\hline 12 & C68-220 & 122.2 & 73.9 & 134.7 & 106.9 & $109.4 \mathrm{cdef}$ & 0.45 \\
\hline 13 & C72-554 & 106.4 & 203.0 & 81.7 & 46.5 & 109.4cdef & 0.38 \\
\hline 14 & C70-244 & 127.8 & 80.3 & 114.9 & 32.7 & 88.9 def & 1.30 \\
\hline 15 & TN 57 & 99.3 & 54.2 & 126.7 & 60.4 & 85.2def & 0.92 \\
\hline 16 & C67-222 & 91.3 & 26.5 & 144.4 & 54.8 & 79.3ef & 1.19 \\
\hline 17 & C72-277 & 113.1 & 66.3 & 87.5 & 24.9 & 73.0f & 1.08 \\
\hline 18 & C70-203 & 72.4 & 81.2 & 84.7 & 49.0 & $71.8 \mathrm{f}$ & 0.43 \\
\hline 19 & C71-66 & 66.6 & 45.7 & 118.2 & 55.0 & $71.4 \mathrm{f}$ & 0.73 \\
\hline 20 & C70-220 & 64.7 & 60.3 & 100.0 & 59.7 & $71.2 \mathrm{f}$ & 0,43 \\
\hline \multicolumn{2}{|c|}{ Mean stock effect } & $131.3 \mathrm{a}^{*}$ & $106.8 b$ & $143.1 \mathrm{a}$ & $72.0 \mathrm{c}$ & 113.3 & \\
\hline \multicolumn{2}{|c|}{ Response of sink to source } & 1.46 & 0.93 & 0.91 & 0.70 & & \\
\hline
\end{tabular}

\footnotetext{
* Means having same letters are not significantly different at $1 \%$ level by Duncan's Multiple Range Test.
} 
Table 4. Dry tuberous root yields (g/plant) of the four tester clones grafted to the 20 experimental sweet potato clones (1987 trial)

\begin{tabular}{|c|c|c|c|c|c|c|c|}
\hline \multirow[t]{2}{*}{ Ranking } & \multirow[t]{2}{*}{ Clone tested } & \multicolumn{4}{|l|}{ Scion } & \multirow{2}{*}{$\begin{array}{l}\text { Mean stoçk } \\
\text { effect }\end{array}$} & \multirow{2}{*}{$\begin{array}{l}\text { Response of } \\
\text { sink to source }\end{array}$} \\
\hline & & C70-245 & C70-200 & C70-311 & $C 70-105$ & & \\
\hline 1 & C70-141 & 129.8 & 253.0 & 116.6 & 93.1 & $148.1 \mathrm{a}^{*}$ & 1.52 \\
\hline 2 & C70-203 & 208.9 & 180.9 & 58.3 & 95.1 & $135.8 \mathrm{ab}$ & 1.50 \\
\hline 3 & C72-738 & 108.0 & 230.5 & 118.7 & 65.8 & $130.8 \mathrm{abc}$ & 1.43 \\
\hline 4 & C68-106 & 216.1 & 141.6 & 80.5 & 74.2 & 128.1abcd & 1.21 \\
\hline 5 & C70-244 & 117.2 & 229.3 & 94.7 & 68.4 & 127.4abcd & 1.57 \\
\hline 6 & TN 66 & 168.6 & 169.8 & 67.9 & 99.4 & 126.4abcd & 1.13 \\
\hline 7 & TN 67 & 147.1 & 168.4 & 90.1 & 88.8 & 123.6abcd & 0.99 \\
\hline 8 & C72-554 & 144.5 & 186.9 & 72.0 & 89.6 & 123.3abcd & 1.24 \\
\hline 9 & C72-38 & 113.8 & 160.0 & 147.4 & 63.4 & 121.2abcd & 0.66 \\
\hline 10 & C72-277 & 176.1 & 136.7 & 58.4 & 82.2 & 113.4abcd & 1.05 \\
\hline 11 & C72-324 & 102.1 & 160.7 & 83.9 & 77.3 & 106.0abcd & 0.85 \\
\hline 12 & C71-66 & 133.9 & 112.3 & 108.4 & 67.8 & $105.6 \mathrm{bcd}$ & 0.48 \\
\hline 13 & TN 57 & 116.2 & 154.8 & 75.1 & 52.1 & $99.6 \mathrm{bcd}$ & 1.11 \\
\hline 14 & C72-769 & 128.9 & 108.3 & 92.6 & 51.8 & $95.4 \mathrm{bcd}$ & 0.64 \\
\hline 15 & C70-220 & 116.3 & 172.6 & 48.4 & 39.8 & $94.3 \mathrm{bcd}$ & 1.52 \\
\hline 16 & TN 64 & 109.2 & 111.1 & 107.6 & 35.5 & $90.9 \mathrm{~cd}$ & 0.63 \\
\hline 17 & C72-130 & 127.0 & 107.0 & 51.4 & 72.3 & $89.4 \mathrm{~cd}$ & 0.68 \\
\hline 18 & C67-222 & 117.5 & 79.4 & 100.4 & 50.8 & $87.0 \mathrm{~d}$ & 0.28 \\
\hline 19 & C68-220 & 99.5 & 138.4 & 59.9 & 46.2 & $86.0 \mathrm{~d}$ & 1.02 \\
\hline 20 & TN 68 & 63.2 & 137.7 & 38.9 & 101.5 & $85.3 \mathrm{~d}$ & 0.52 \\
\hline \multicolumn{2}{|c|}{ Mean scion effect } & $132.2 b^{*}$ & $157.0 \mathrm{a}$ & $83.6 \mathrm{c}$ & $70.8 \mathrm{c}$ & 110.9 & \\
\hline \multicolumn{2}{|c|}{ Response of source to sink } & 1.07 & 1.82 & 0.52 & 0.60 & & \\
\hline
\end{tabular}

* Means having same letters are not significantly different at 1\% level by Duncan's Multiple Range Test.

confirmed our early finding ( $\mathrm{Li} \& \mathrm{Kao}, 1985 \mathrm{a})$, that C70-311 and C70-105 had high and low sink capacities, respectively. No significant correlation was observed between the source potentials and the responses of sources to sinks (Fig. 1).

Table 5. Average dry tuberous root yields of 12 plants for 20 sweet potato clones without grafting (1987 trial)

\begin{tabular}{lc}
\hline Clone tested & Yield (g/plant) \\
\hline TN 64 & 245.1 \\
C70-141 & 235.3 \\
C72-130 & 233.4 \\
C72-738 & 218.6 \\
C68-106 & 203.1 \\
C72-769 & 196.0 \\
C72-554 & 195.3 \\
C72-324 & 193.5 \\
C68-220 & 190.1 \\
TN 68 & 181.9 \\
TN 66 & 181.3 \\
C72-38 & 172.6 \\
TN 67 & 168.5 \\
C72-277 & 142.1 \\
C71-66 & 136.0 \\
C70-244 & 129.4 \\
TN 57 & 115.6 \\
C70-220 & 113.7 \\
C70-203 & 93.4 \\
C67-222 & 72.4 \\
\hline
\end{tabular}

The sink capacities and degrees of response of sink to source of the 13 experimental clones are summarized in Table 2 . There were significant differences at the $1 \%$ level among the sink capacities of the 13 clones tested, and also among the source potentials of the four tester clones. C70-245 was demonstrated to be a good source, whereas C70105 a poor source. These results are in agreement with our early work ( $\mathrm{Li} \& \mathrm{Kao}, 1985 \mathrm{a}$ ). The degrees of responses of sink to source were plotted against respective sink capacities (Fig. 2). In general, clones with high sink capacities showed high responses of sinks to sources.

\section{7 trial}

The results of 1987 trial are, in general, consistent with those of 1986 trial, though different clones were used. Both source potentials and sink capacities were significantly different among the 20 experimental clones at the $1 \%$ level (Tables 3 and 4). Results also demonstrated that $\mathrm{C} 70-245$ was a good source whereas C70-311 was a good sink. C70-105 


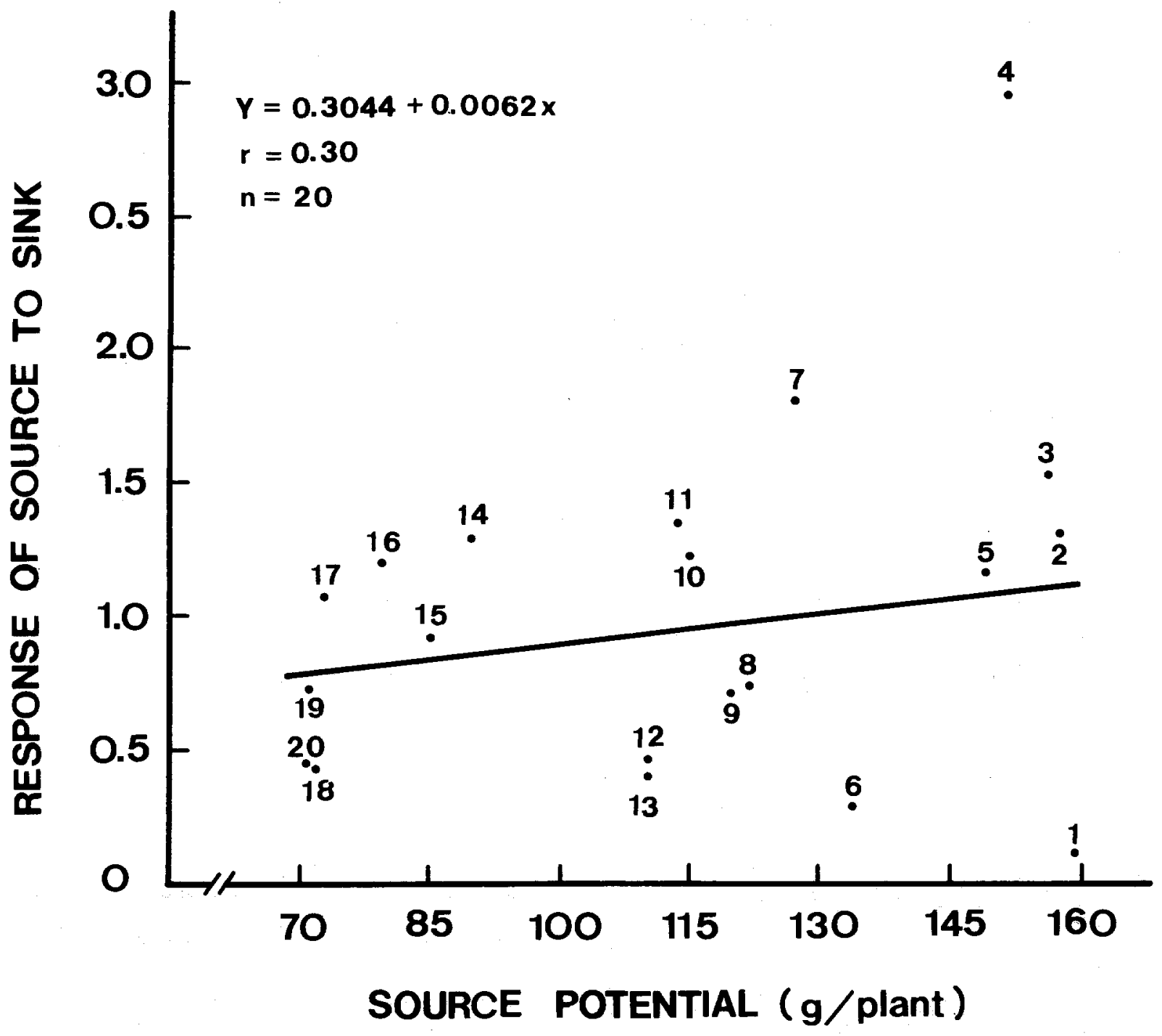

Fig. 3. Relation between source potential (x) and response of source to sink (y) for 20 experimental sweet potato clones (1987 trial). The numbers by points refer to clones ranking in Table 3 .

was found to be poor in both source potential and sink capacity. As in 1986 trial, no correlation was observed between the source potentials and responses of sources to sinks (Fig. 3). However, sink capacities were highly correlated with responses of sinks to sources (Fig. 4). In order to determine the relative contribution of source potential and sink capacity to the tuberous root yield, a yield trial of the 20 experimental clones without grafting was conducted simultaneously. The results were presented in Table 5.

\section{Discussion}

Grafting procedures, though tedious and laborious, permit us to screen the source potentials and sink capacities of sweet potatoes. Our present study clearly confirmed the early reports by Hahn $(1977,1982)$ that source potentials and sink capacities varied among clones or cultivars.

The dry tuberous root yield of sweet potato is dependent on source potential and sink capacity. Recently, Bouwkamp \& Hassam (1988) demon- 


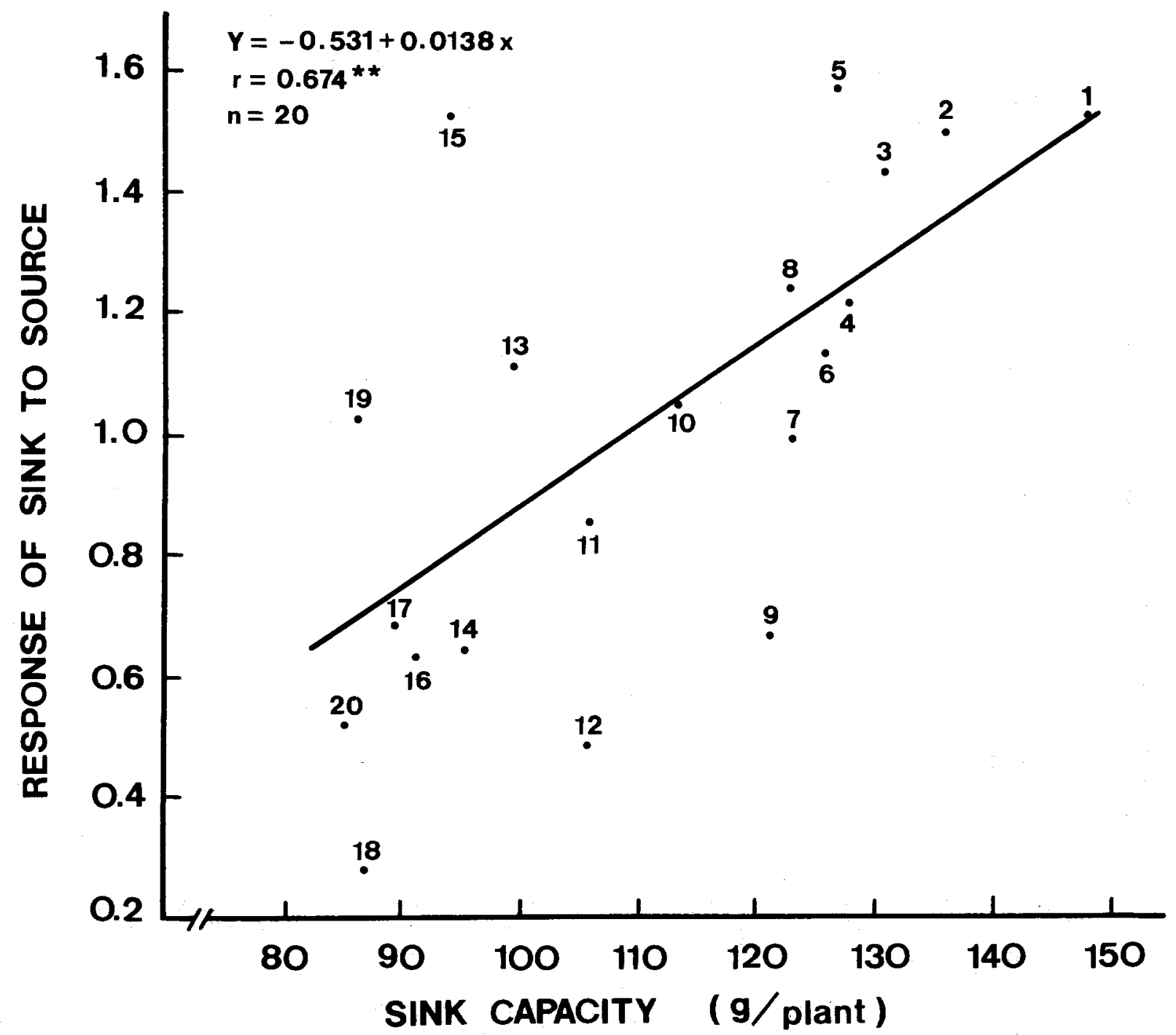

Fig. 4. Relation between sink capacity (x) and response of sink to source (y) for 20 experimental sweet potato clones (1987 trial). The numbers by points refer to clones ranking in Table 4 .

strated that the relative importances of source potential and sink capacity changed during the growing season and differed among cultivars. Under their conditions, source potentials predominated over sink capacities in terms of effects on dry tuberous root yield. In our previous work, we also reported that the relative contribution of source potential and sink capacity to dry tuberous root yield was dependent upon growth period ( $\mathrm{Li} \& \mathrm{Kao}$, $1985 b$ ). Source potential was more limiting than sink capacity when growth period was 4 months, but they are equally important when growth period was 6 months. In the present study, the growth period was 5 months. TN 64 and C72-130 had the highest yields among the 20 experimental clones (Table 5). These two clones had good source potentials but poor sink capacities. Other high-yielding clones such as C70-141, C72-738, C68-106 and C72-769 showed both high source potentials and sink capacities. Low-yielding clones such as C67222 and C70-220 were observed to be poor in both source and sink. Another low-yielding clone was C70-203, showed high sink capacity but low source potential. Thus, source potential appears to be more important than sink capacity when growth period was 5 months. 
Assimilate translocation is determined by the photosynthetic capacity of source, and sink activity. Sink activity alters the photosynthetic capacity through affecting assimilate translocation which is regarded as response of source to sink. By contrast response of sink to source refers to the changes in sink capacity when photosynthetic capacity changes. Hahn (1982) demonstrated that source potential showed significant relationship with response of source to sink, which contradicts what we presented here. Our results seem to suggest that the clones with high source potentials do not necessarily have high response of source to sink. It means that photosynthetic capacity of a clone with high source potential is unlikely to be altered by the change of sink capacity. The discrepancy between Hahn's results and ours is possibly due to different growth period used. The growth period of Hahn's experiment was 3 months, whereas that of ours was 5 months.

Although TN 64 had the highest yield and source potential of the experimental clones, this clone had the lowest response of source to sink (Table 3 and 5). It is likely that the assimilate translocation of TN 64 is less sensitive to the changes of sink activity.

It has been shown that high-yielding genotypes generally partitioned more photosynthate to tuberous roots than low-yielding genotypes (Bhagsari \& Harmon, 1982; Huett, 1976; Li \& Kao, 1985b). In the present investigation, a significant relationship was found between sink capacity and response of sink to source. Accordingly, selection of clones with high sink capacities and ideal degrees of re- sponse of sink to source is possible. In other words, selection for large sink will, to a certain extent, lead to improvement of translocation capacity.

\section{Acknowledgement}

This research was supported by the Council of Agriculture, Republic of China.

\section{References}

Bhagsari, A.S. \& S.A. Harmon, 1982. Photosynthesis and photosynthate partitioning in sweet potato genotypes. J. Amer. Soc. Hort. Sci. 107: 506-510.

Bouwkamp, J.C. \& M.N.N. Hassam, 1988. Source-sink relationships in sweet potato. J. Amer. Soc. Hort. Sci. 113: 627629.

Hahn, S.K., 1977. A quantitative approach to source potentials and sink capacities among reciprocal grafts of sweet potato varieties. Crop Sci. 17: 559-562.

Hahn, S.K., 1982. Screening sweet potato for source potentials. Euphytica 31: 13-18.

Hozyo, Y., 1970. Growth and development of tuberous root in sweet potato. Proc. Intl. Symp. Trop. Root Crops 2: 22-23.

Huett, D.O., 1976. Evaluation of yield variability quality of sweet potato cultivars in subtropical Australia. Expl. Agric. 12: 9-16.

Li, L. \& C.H. Kao, 1985a. Investigation of source-sink relationship in sweet potato by reciprocal grafts. Bot. Bull. Academia Sinica 26: 31-38.

Li, L. \& C.H. Kao, 1985b. Dry matter production and partition of six sweet potato (Ipomoea batatas L.) cultivars. J. Agric. Assoc. China (New series) 131: 10-23.

Wilson, L.A., 1967. The use of rooted leaves and graft plants for the study of carbohydrate metabolism in sweet potato. Proc. Intl. Symp. Trop. Root Crops 1: 46-57. 